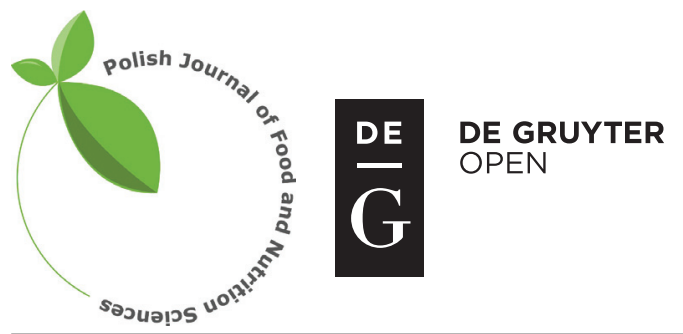

Pol. J. Food Nutr. Sci., 2016, Vol. 66, No. 1, pp. 43-49 DOI: $10.1515 /$ pjfns-2015-0014 http://journal.pan.olsztyn.pl

Original article

Section: Nutritional Research

\title{
Effects of Silybum marianum Extract on High-Fat Diet Induced Metabolic Disorders in Rats
}

\author{
Fatma Kubra Sayin ${ }^{1 *}$, Sadik Buyukbas ${ }^{2}$, M. Kemal Basarali ${ }^{3}$, Harun Alp ${ }^{4}$, Hatice Toy , Veli Ugurcu $^{6}$ \\ ${ }^{1}$ Department of Nutrition and Dietetics, Health Sciences Faculty, Necmettin Erbakan University, Konya, Turkey \\ ${ }^{2}$ Department of Biochemistry, Meram Medical Faculty, Konya Necmettin Erbakan University, Konya, Turkey \\ ${ }^{3}$ Department of Biochemistry, Medical Faculty, Dicle University, Diyarbakur, Turkey \\ ${ }^{4}$ Department of Pharmacology and Toxicology, Medical Faculty, Mustafa Kemal University, Hatay, Turkey \\ ${ }^{5}$ Department of Pathology, Meram Medical Faculty, Konya Necmettin Erbakan University, Konya, Turkey \\ ${ }^{6}$ Private Bilecik Orhangazi Dialysis Center, Bilecik, Turkey
}

Key words: Silybum marianum, cholesterol, insulin, leptin, high-fat diet

Silybum marianum extract (SME) has been used for centuries as a natural remedy for diseases of liver and biliary tract. Lately, it has been promoted as a nutritional supplement for beneficial effects on some risk factors of diabetes and hyperlipidemia. In this study we aimed to determine the effects of SME on high-fat diet (HFD) induced metabolic disorders. Male Sprague Dawley rats were fed HFD for 11 weeks to induce obesity. SME was given to animals for two different durations, for 11 weeks or for 7 weeks. The results showed significant increase in plasma transaminases, total cholesterol (TC), triglycerides (TG), low density lipoprotein cholesterol (LDL-C), leptin, high sensitive C-reactive protein (hsCRP), glucose and insulin along with significant increase in body mass index (BMI) and liver weights in rats fed the HFD diet compared to rats fed with standard rat diet. SME supplementation for different durations raised improvement in the HFD-induced metabolic disorders such as insulin resistance, hyperlipidemia and hepatopathy at different degrees. Our study concludes that SME can be well considered as an effective supplement to improve insulin and leptin sensitivity and hyperlipidemia and to suppress body weight gain.

\section{INTRODUCTION}

Obesity and associated disorders have increased significantly worldwide in the last decades and pose serious risks to the present and future health of humankind [Poirier et al., 2006]. Obesity alone can induce many additional health problems, including increased risk of insulin resistance, non-alcoholic fatty liver, atherosclerosis, degenerative disorders such as dementia, some immune-mediated disorders such as asthma, and certain cancers [Barness et al., 2007].

Today, even well-structured calorie restriction and exercise programs that are supported by behavioral therapy may not be sufficient to overwhelm obesity [Maguire \& Haslam, 2010]. Thus, some potential herbs are being investigated and tested which may allow effective and reliable anti-obesity therapy with little side effect. Recently, it has been established that many herbal extracts can provide weight control by influencing lipid and carbohydrate metabolism. Some of these supplements, including Ephedra sinica, Paullinia cupana, Plantago psyllium, and Pausinystalia yohimbe, have harmful effects, whereas Garcinia cambogia and Ilex paraguariensis are considered relatively safe and merit further investigation [Pittler et al., 2005].

\footnotetext{
* Corresponding Author: Tel.: 0090-5303459574;

E-mail: kubrakucur@hotmail.com.tr (Fatma Kubra Sayin)
}

Silybum marianum is a plant that has been used for centuries as a natural remedy for liver and biliary tract diseases [Pradhan \& Girish, 2006]. The active extract of S. marianum, known as silymarin, is a mixture of flavanolignans namely; silibinin, silydianin, and silychristine [Wagner \& Seligmann, 1985]. The S. marianum extract (SME) has strong antioxidant activity and exhibits anti-inflammatory and cytoprotective effects [Pradhan \& Girish, 2006; Kren \& Walterová, 2005]. In addition, it has been demonstrated that the extract protects hepatocytes against a variety of toxins including ethanol, free fatty acids, carbon tetrachloride, acetaminophen and phenylhydrazine [Pradhan \& Girish, 2006; Kren \& Walterová, 2005; Ramakrishnan et al., 2006; Abenavoli et al., 2010]. It has been also found that silymarin had protective effect against lipid peroxidation [Lahiri-Chatterjee et al., 1999], inhibitory effect on low density lipoprotein oxidation [Skottova et al., 1999] and controlling effect on reactive oxygen species [Dehmlow et al., 1996].

Although numerous studies have examined the different medicinal properties of $S$. marianum and its constituents, S. marianum, however, has not been investigated for its therapeutic and protective potential versus obesity related metabolic disorders. There are data showing that high-fat diet fed animal models are useful tools to induce adipogenesis and the metabolic syndrome and to evaluate the efficacy 
of potential compounds in the treatment of obesity [Bulló et al., 2007; Lim et al., 2013; BrahmaNaidu et al., 2014]. Thus, the aim of the present study was to evaluate the time-dependent effects of S. marianum on HFD-related metabolic disorders and weight increase. For evaluating therapeutic effects of $S$. marianum we planned to give the extract to rats for last 7 weeks, for evaluating its preventive effects we used the extract from the beginning of the study for 11 weeks. HFD-related biochemical parameters planned to be assessed included liver functions, serum lipid profile, glucose, insulin, leptin and high sensitive $\mathrm{C}$ reactive protein (hsCRP) levels in plasma along with histopathological examination of the liver.

\section{MATERIALS AND METHODS}

\section{Animal model and experimental design}

This study was approved by Ethic Committee of Experimental Medical Research and Application Center of Selcuk University. It was performed on 40 male Sprague-Dawley rats weighing $80-100 \mathrm{~g}$, which were $8 \mathrm{wk}$ old at the beginning of experiment. All rats housed in stainless steel cages were placed in a room at $22-25^{\circ} \mathrm{C}$. Rats were housed in $12: 12 \mathrm{~h}$ light-dark cycle at a humidity of $50 \pm 5 \%$. Rats were fed standard laboratory chow diet and water ad libitum for 1 week to stabilize their metabolic condition. After the 1-week adaptation, the animals were randomly divided into four groups:

- Group $1(n=10)$ : Animals were treated with a standard laboratory rat diet (SD) for $11 \mathrm{wk}$.

- Group $2(n=10)$ : Animals were treated with HFD for $11 \mathrm{wk}$.

- Group $3(n=10)$ : Animals were treated with HFD for $7 \mathrm{wk}$ and then SME $(200 \mathrm{mg} / \mathrm{kg} /$ day $)$ added diet for the last $4 \mathrm{wk}$.

- Group $4(n=10)$ : Animals were treated with HFD and SME (200 mg/kg/day) for $11 \mathrm{wk}$.

The rats had free access to food and water, and their food intake was measured daily while their body weight was measured twice a week. The composition of the diet for each experimental group is shown in Table 1. Standard laboratory diet included $12 \%$ calories as fat with an energy density of $3.50 \mathrm{kcal} / \mathrm{g}$ and HFD contained 54\% calories as fat with an energy density of $4.90 \mathrm{kcal} / \mathrm{g}$ [Terra et al., 2011]. The diets were given in the form of pellets. SME doses were determined at $200 \mathrm{mg} / \mathrm{kg} /$ day in the light of the studies by Crocenzi et al. [2000], Chen et al. [2012], and Tsai et al. [2008].

At the end of the study, total food intake, body weight gain and food efficiency ratio (body weight gain/total food intake $\mathrm{x}$ 100) were calculated.

\section{Collection of serum and tissue samples}

After 11 weeks of treatment, the rats were fasted for $12 \mathrm{~h}$ and then blood samples were collected through direct cardiac puncture under ketamine/xylazine anesthesia and rats were euthanized by cervical decapitation. Blood samples taken from the rats were centrifuged at $1,000 \times \mathrm{g}$ for $10 \mathrm{~min}$ and serum samples were stored at $-20^{\circ} \mathrm{C}$ until biochemical analysis. Livers were immediately excised, weighed, divided into smaller pieces and fixed in 4\% paraformaldehyde for histological analysis.
TABLE 1. Composition of diets $(\mathrm{g} / \mathrm{kg})$.

\begin{tabular}{lcccc}
\hline Ingredients & $\begin{array}{c}\text { Standart } \\
\text { diet }\end{array}$ & $\begin{array}{c}\text { High-fat } \\
\text { diet }\end{array}$ & $\begin{array}{c}\text { High-fat } \\
\text { +SME diet }\end{array}$ \\
\hline Total protein & 200 & 200 & 200 \\
Total carbohydrate & 580 & 400 & 400 \\
Total fat & 50 & 280 & 280 \\
Sun flower oil + corn oil & 50 & 30 & 30 \\
Lard & 0 & 250 & 250 \\
Vitamin and mineral mix. & 45 & 45 & 45 \\
Cellulose & 60 & 45 & 45 \\
S. marianum extract & 0 & 0 & 15 \\
\hline
\end{tabular}

\section{Measurement of body and organ weights}

Body weight and length was measured twice a week during the feeding period. Body mass index (BMI) was determined in all animals as reported previously by other authors [Novelli et al., 2007], using the formula: BMI=body weight (g)/ length ${ }^{2}\left(\mathrm{~cm}^{2}\right)$, where "length" corresponds to the "nose-to-anus" length. At sacrifice, the weights of livers was measured.

\section{Chemicals}

SME was provided by Gaia Herbs Inc. (USA) and contained Silymarin of $80 \%$ and soy lecithin of $20 \%$ in addition to plant glycerin and cellulose.

\section{Biochemical analyses of plasma}

Serum triglyceride (TG), total cholesterol (TC), high-density lipoprotein cholesterol (HDL-C), alanine aminotransferase (ALT), aspartate aminotransferase (AST), gamma glutamyltransferase (GGT), high sensitive $\mathrm{C}$ reactive protein (hsCRP) and glucose levels were analyzed by photometric method using auto-analyzer kit according to methods defined by Rautela et al. [1974], Raja et al. [2007], Rautela \& Liedtke [1978], Warnick \& Wood [1995], Wroblewski \& LaDue [1956], Bergmeyer et al. [1978] and Shaw et al. [1983]. Low-density lipoprotein cholesterol (LDL-C) levels were estimated according to Friedewald formula. All lipoprotein levels were recorded as $\mathrm{mg} / \mathrm{dL}$. Serum leptin levels were measured by using Biovendor ELISA kit, whereas serum insulin levels were analyzed by sandwich ELISA technique and Biovendor kit. HOMA-IR was calculated as: (fasting serum glucose $\times$ fasting serum insulin) / 22.5.

\section{Histological evaluation of liver}

Formaldehyde-fixed liver tissues were embedded in paraffin. Five-micrometer-thin sections were obtained and stained with hematoxylin and eosin (HE). Liver sections were observed by fluorescence microscope. The steatosis/steatohepatitis was evaluated using a semi-quantitative scoring system [Wei et al., 2008]. The scoring was based on a chow diet group of animals for which if liver acini did not show lipid vacuoles, a score of zero was given (baseline). Acini having lipid vacuoles up to $33 \%$ (mainly macro vesicular type) were considered as score 1. Acini with 34-66\% of lipid vacuoles were scored 2 while acini having over $66 \%$ of lipid vacuoles were ranked 3 . 


\section{Statistical analysis}

SPSS for Windows (version 16.0) (SPSS, Inc., Chicago, IL) was used for statistical evaluation of the data. All data are expressed as mean \pm SD values. Analysis of variance with Kruskal-Wallis test was used to compare means of 4 groups. Pairwise comparisons of the study groups were performed using Mann Whitney $\mathrm{U}$ test. $\mathrm{P}$ values of $<0.05$ were considered significant.

\section{RESULTS}

\section{Effect of SME on HFD-induced obesity}

The effect of SME on growth characteristics is shown in Table 2. Daily food intake per cage did not differ among groups. After 11 wk of treatment, rat body weights and BMI were significantly higher in the HFD group compared with that in SD group $(\mathrm{p}<0.05)$. Treatment with SME for $11 \mathrm{wk}$ decreased final weight and final BMI significantly $(p<0.05)$, but no significant decrease was achieved when it was given during the last 4 wk compared with HFD group. Leptin levels were significantly higher in HFD fed rats compared with SD group, and SME treatment for $4 \mathrm{wk}$ and for $11 \mathrm{wk}$ induced a significant decrease in serum leptin levels $(\mathrm{p}<0.01)$ (Table 3). Also hsCRP levels were significantly higher in HFD fed rats compared with SD group, and SME treatment for $4 \mathrm{wk}$ and for $11 \mathrm{wk}$ induced a significant decrease in serum hsCRP levels $(\mathrm{p}<0.05)$ (Table 3$)$.

\section{Effect of SME on HFD-induced hyperlipidemia}

As shown in Table 3 rats fed a diet enriched with lard fat for $11 \mathrm{wk}$ developed hyperlipidemia. The levels of TC, TG and LDL-C in plasma were significantly lower in the groups treated with SME for 4 and 11 wk compared with HFD group, demonstrating that dietary supplementation with SME improves lipid profiles.

\section{Effect of SME on HFD-induced hepatopathy}

Serum levels of ALT and GGT were significantly higher in HFD group than in the SD group but SME treat- ment for $4 \mathrm{wk}$ and for $11 \mathrm{wk}$ induced a significant decrease $(p<0.01$ and $p<0.05$, respectively). There was no significant difference in serum AST levels (Table 3). Rat liver sections were stained with hematoxylin \& eosin ( $\mathrm{H} \& \mathrm{E})$ to assess fat accumulation. The fat deposition (lipid droplets) in stained sections of the HFD fed animals was of macro vesicular type. Based on the scoring method [Wei et al., 2008], the HFD fed animals showed histopathological features of hepatic steatosis with a score of 2 indicating that over 33\% of acini were occupied by lipid vacuoles compared to SD fed animals. There were clear, well delineated and the cytoplasmic vacuoles in the hepatocytes were of variable sizes. There were lipid vacuoles in the liver of HFD rats compared to the SD group and SME groups. It could be concluded then that the HFD animals displayed histopathological features of hepatic steatosis and SME supplementation improved it.

\section{Effect of SME on HFD-induced insulin resistance}

As shown in Table 3 serum insulin levels and HOMA-IR values were significantly increased in HFD fed rats compared with SD group, and SME treatment for $4 \mathrm{wk}$ and for $11 \mathrm{wk}$ induced a significant decrease in serum insulin levels $(\mathrm{p}<0.001$ and $\mathrm{p}<0.01$, respectively).

\section{DISCUSSION}

HFD is widely used in the experimental induction of weight gain and obesity in animals [Kim et al., 2000; Mashmoul et al., 2014; You et al., 2014]. In the results of this study, HFD feeding for $11 \mathrm{wk}$ resulted in obesity, which was associated with increased body weight and BMI with development of hyperlipidemia. After the SME treatment for $4 \mathrm{wk}$, BMI and body weight did not alter significantly while SME treatment for $11 \mathrm{wk}$ significantly decreased BMI and body weight. Increase in the influx of greater amounts of non-esterified fatty acids to liver causes an increase in triacylglycerol level which may cause dyslipidemic changes in the obesity [Grundy et al., 2004]. It has been demonstrated that changes in lipid concentrations and lipoprotein fractions are associated with

TABLE 2. Body weight and BMI of control and experimental groups.

\begin{tabular}{lcc|c|c}
\hline & SD $(\mathrm{n}=10)$ & HFD $(\mathrm{n}=10)$ & SME for 4 wk $(\mathrm{n}=10)$ & SME for 11 wk $(\mathrm{n}=10)$ \\
\hline Initial body weight $(\mathrm{g})$ & $83.55 \pm 18.10^{\mathrm{a}}$ & $90.75 \pm 28.72^{\mathrm{a}}$ & $90.80 \pm 8.28^{\mathrm{a}}$ & $86.11 \pm 28.63^{\mathrm{a}}$ \\
Final body weight (g) & $220.55 \pm 30.17^{\mathrm{a}}$ & $286.87 \pm 33.49^{\mathrm{b}}$ & $272.4 \pm 28.58^{\mathrm{b}}$ & $249.11 \pm 31.71^{\mathrm{a}}$ \\
Body weight gain (g) & $137.12 \pm 31.77^{\mathrm{a}}$ & $195.38 \pm 26.46^{\mathrm{b}}$ & $184.42 \pm 29.40^{\mathrm{b}}$ & $162.22 \pm 30.47^{\mathrm{b}}$ \\
Initial BMI (g/cm) & $0.45 \pm 0.05^{\mathrm{a}}$ & $0.47 \pm 0.06^{\mathrm{a}}$ & $0.45 \pm 0.07^{\mathrm{a}}$ & $0.46 \pm 0.09^{\mathrm{a}}$ \\
Final BMI (g/cm) & $0.62 \pm 0.11^{\mathrm{a}}$ & $0.87 \pm 0.46^{\mathrm{b}}$ & $0.77 \pm 0.05^{\mathrm{a}}$ & $0.65 \pm 0.08^{\mathrm{a}}$ \\
BMI gain (g/cm) & $0.17 \pm 0.05^{\mathrm{a}}$ & $0.40 \pm 0.07^{\mathrm{b}}$ & $0.32 \pm 0.09^{\mathrm{b}}$ & $0.19 \pm 0.08^{\mathrm{a}}$ \\
Liver weight (g) & $3.81 \pm 0.54^{\mathrm{a}}$ & $4.22 \pm 0.68^{\mathrm{b}}$ & $3.94 \pm 0.66^{\mathrm{a}}$ & $3.90 \pm 0.76^{\mathrm{a}}$ \\
Food intake (g/day) & $18.35 \pm 0.34^{\mathrm{a}}$ & $16.93 \pm 0.49^{\mathrm{b}}$ & $15.75 \pm 1.42^{\mathrm{b}}$ & $15.18 \pm 1.21^{\mathrm{b}}$ \\
Food efficiency ratio (\%) & $9.72 \pm 0.98^{\mathrm{a}}$ & $15.22 \pm 1.69^{\mathrm{b}}$ & $14.94 \pm 2.52^{\mathrm{b}}$ & $13.88 \pm 1.55^{\mathrm{b}}$
\end{tabular}

${ }^{1}$ Results are the mean value \pm standard deviation. Different letters in the same row indicate significant differences, $\mathrm{p}<0.05 .{ }^{2} \mathrm{BMI}$, body mass index; SD, standard diet group; HFD, high-fat diet group; SME for 4 wk, high-fat diet + S. marianum extract for 4 wk group; SME for 11 wk, high-fat diet + S. marianum extract for $11 \mathrm{wk}$. 
TABLE 3. Serum lipid concentrations, leptin, AST, ALT, GGT and hsCRP levels in control and experiment groups.

\begin{tabular}{lccccc}
\hline & SD $(\mathrm{n}=10)$ & HFD $(\mathrm{n}=10)$ & SME for 4 wk $(\mathrm{n}=10)$ & SME for 11 wk (n=10) \\
\hline TG (mg/dL) & $27.33 \pm 4.38^{\mathrm{a}}$ & $41.55 \pm 14.45^{\mathrm{b}}$ & $36.11 \pm 16.63^{\mathrm{b}}$ & $27.88 \pm 8.55^{\mathrm{a}}$ \\
TC (mg/dL) & $70.33 \pm 15^{\mathrm{a}}$ & $93.33 \pm 15.26^{\mathrm{b}}$ & $71.44 \pm 7.81^{\mathrm{a}}$ & $78.22 \pm 8.70^{\mathrm{b}}$ \\
HDL-C (mg/dL) & $18.66 \pm 4.82^{\mathrm{a}}$ & $23.22 \pm 6.05^{\mathrm{b}}$ & $23.77 \pm 7.13^{\mathrm{b}}$ & $25.11 \pm 5.70^{\mathrm{b}}$ \\
LDL-C (mg/dL) & $43.55 \pm 9.12^{\mathrm{a}}$ & $57.00 \pm 13.96^{\mathrm{b}}$ & $40.11 \pm 7.41^{\mathrm{a}}$ & $45.00 \pm 7.84^{\mathrm{a}}$ \\
Leptin (pg/L) & $2.32 \pm 0.294^{\mathrm{a}}$ & $3.168 \pm 0.353^{\mathrm{b}}$ & $1.754 \pm 0.298^{\mathrm{a}}$ & $2.367 \pm 0.368^{\mathrm{a}}$ \\
ALT (U/L) & $102.42 \pm 24.31^{\mathrm{a}}$ & $154.5 \pm 6.46^{\mathrm{b}}$ & $120.36 \pm 3.21^{\mathrm{a}}$ & $99.97 \pm 19.85^{\mathrm{a}}$ \\
AST (U/L) & $50.25 \pm 9.44^{\mathrm{a}}$ & $58.68 \pm 14.7^{\mathrm{a}}$ & $47.70 \pm 13.95^{\mathrm{a}}$ & $50.15 \pm 7.23^{\mathrm{a}}$ \\
GGT (U/L) & $13.91 \pm 4.10^{\mathrm{a}}$ & $18.36 \pm 6.07^{\mathrm{b}}$ & $11.77 \pm 4.88^{\mathrm{a}}$ & $11.51 \pm 4.24^{\mathrm{a}}$ \\
hsCRP (mg/dL) & $3.24 \pm 1.18^{\mathrm{a}}$ & $4.98 \pm 1.71^{\mathrm{b}}$ & $2.40 \pm 0.88^{\mathrm{a}}$ & $2.02 \pm 0.69^{\mathrm{a}}$ \\
Glucose (mg/dL) & $140.11 \pm 37.45^{\mathrm{a}}$ & $279.87 \pm 44.88^{\mathrm{b}}$ & $246.5 \pm 92.86^{\mathrm{b}}$ & $281.5 \pm 33.56^{\mathrm{b}}$ \\
Insulin (ng/mL) & $20.04 \pm 2.68^{\mathrm{a}}$ & $30.82 \pm 2.61^{\mathrm{b}}$ & $21.77 \pm 2.26^{\mathrm{a}}$ & $20.01 \pm 3.12^{\mathrm{a}}$ \\
HOMA-IR & $1.27 \pm 0.44^{\mathrm{a}}$ & $3.85 \pm 0.85^{\mathrm{b}}$ & $2.43 \pm 0.42^{\mathrm{c}}$ & $2.46 \pm 0.53^{\mathrm{c}}$ \\
\hline
\end{tabular}

${ }^{1}$ Results are the mean value \pm standard deviation. Different letters in the same row indicate significant differences, $\mathrm{p}<0.05$. ${ }^{2} \mathrm{TG}$, triglyceride; TC, total cholesterol; HDL-C, high-density lipoprotein cholesterol; LDL-C, low-density lipoprotein cholesterol; AST, aspartate aminotransferase; ALT, alanine aminotransferase; GGT, gamma glutamyltransferase; BMI, body mass index; HOMA IR, homeostasis model assessment insulin resistance; hsCRP, High sensitive C reactive protein; SD, standard diet group; HFD, high-fat diet group; SME for 4 wk, high fat diet + S. marianum extract for 4 wk group; SME for $11 \mathrm{wk}$, high-fat diet + S. marianum extract for $11 \mathrm{wk}$.

the increased risk for obesity-related metabolic conditions. It has been found that obesity is a significant risk factor for the development of dyslipidemia [Montani et al., 2004; Fried et al., 2008] and steatohepatitis [Marovic et al., 2008].

A number of studies were addressed to assess whether SME could effectively ameliorate lipoprotein profile in rats [Haddad et al., 2011; Skottova et al., 2003; Gopalakrishnan et al., 2009]. In one of them, rats were fed with a high-fat liquid diet until they had fatty liver and then were treated with Silibin for $12 \mathrm{wk}$. The treatment decreased TC but not significantly, besides it induced a significant decrease in LDL-C levels [Haddad et al., 2011]. In other animal models the SME was also shown to be effective to reduce cholesterol at high cholesterol fed rats [Skottova et al., 2003] and hepatocellular carcinoma [Gopalakrishnan et al., 2009]. Also, silymarin reduced cholesterol absorption in rats fed on high cholesterol diet and caused significant decreases in VLDL, cholesterol and TG in the liver [Sobolova et al., 2006]. Hence, the inhibition of cholesterol absorption by silymarin could be a mechanism contributing to the positive changes in plasma cholesterol lipoprotein profile [Sobolova et al., 2006].

In agreement to the above-mentioned studies, dyslipidemic changes manifested with increased levels of TG, TC and LDL-C were seen in the rats receiving HFD when compared to controls in the present study. Again, it was found that HDL-C levels were higher in the rats given SME than in the control groups. Interestingly, HDL-C level was increased only in rats receiving HFD. This indicates that different mechanisms may have role in the lipid metabolism of rats, which are currently unknown.

A HFD may increase the synthesis of fatty acids in the liver and the delivery of free fatty acids to the liver. It may also decrease $\beta$-oxidation of free fatty acids, which may, in turn, cause fat accumulation in the liver. Therefore, fat in hepatocytes results in cellular dysfunction and may damage the liver parenchyma. One of the most sensitive and dramatic indicators of hepatocyte injury is the release of intracellular enzymes such as transaminase in circulation. In our study, SME treatment has ameliorated ALT and GGT levels increased by HFD, which was in accordance with the data of Raja et al. [2007]. Moreover, there was no significant difference between groups regarding AST levels. SME has also been shown to have favorable effects on other metabolic risk factors including fatty liver disease.

Although there are some researches that investigated the effects of $S$. marianum in HFD fed rats, these studies aimed to develop non-alcoholic fatty liver disease (NAFLD) not obesity so their dietary contents were different from ours. In one of them, Haddah et al. [2011] used a dietary model that reproduced the clinical features of NASH in rats and SME induced amelioration in liver steatosis and inflammation, decreased plasma levels of ALT, AST and tumor necrosis factor- $\alpha$ (TNF- $\alpha$ ) and transforming growth factor- $\beta$ (TGF- $\beta$ ). Investigations show that SME exhibits excellent hepatoprotective property by restoring the hepatic marker enzymes and antioxidant property reversing the oxidant-antioxidant imbalance during CCL4, diethyl nitrosamine or methotrexate-induced oxidative stress in rats [Mao et al., 2012; El Mesallamy et al., 2011; Ghaffari et al., 2011]. Silymarin reduced high fructose diet-mediated increase in plasma pro-inflammatory cytokines, C-reactive protein (CRP), interleukin-6 (IL-6), interferon-gamma (IFN- $\gamma$ ) and tumor necrosis factor (TNF) levels [Prakash et al., 2014]. It has been shown that hsCRP level which is one of the inflammation markers, is increased in obesity, as it is an inflammation-related process [Amasyali et al., 2010]. In a study by Galleti 



FIGURE 1. The effect of the SME on lipid deposition of hepatic tissue of rats after staining: (A) SD, standard diet group; (B) HFD, high-fat diet group; (C) SME for $4 \mathrm{wk}$, high fat diet + S. marianum extract for $4 \mathrm{wk}$ group; (D) SME for $11 \mathrm{wk}$, high-fat diet + S. marianum extract for $11 \mathrm{wk}$.

et al. [2007], it was found that increased hsCRP levels were correlated to increase in leptin and HOMA-IR values independent of BMI and fat distribution in overweight individuals.

The results reported here confirm that HFD does induce insulin resistance and mimics the metabolic characteristics of type 2 diabetes, with increase in blood glucose and body weight, as observed by study of Hamza et al. [2010]. Many studies have reported that HFD might be a good way to initiate the insulin resistance [Flanagan et al., 2008; Tanaka et al., 2007] which is the consequence of a number of defects including impaired insulin secretion by the pancreatic cell, resistance of peripheral tissues to the glucose utilizing effect of insulin and augmented hepatic glucose production [Shulman et al., 2000]. Decreased glycolysis impeded glycogenesis and increased gluconeogenesis are some of the changes of glucose metabolism in the diabetic liver [Baquer et al., 1998].

On the other hand, our results show that silymarin is able to ameliorate insulin resistance, evaluated by measuring glucose and insulin levels. Our observations of impaired HOMA-IR levels in HFD fed rats are consistent with previous reports [Falasca et al., 2008; Trappoliere et al., 2005; Vengerouskii et al., 2007; Prakash et al 2014]. Also, it significantly reduced hemoglobin Alc (HbAlc) levels and BMI in type2 diabetic patients [Abdul \& Hussain, 2007]. Silymarin can improve pancreatic morphology and endocrine function, as well as the pancreatic activity of antioxidant enzymes and glutathione, in diabetic models [Soto et al., 2003, 2004]. These effects may decrease serum glucose and serum insulin. Silibinin, a widely used flavonolignan from S. marianum, decreased the HOMA-IR level in obese diabetic mice [Volti et al., 2011] and methionine-choline deficient diet fed mice [Salamone et al., 2012]. Additionally, the effect of SME on hepatic steatosis may contribute to its effects on insulin resistance [Prakash et al., 2014]. Hepatic steatosis is associated with insulin resistance in humans and studies in rodent models have shown that suppression of hepatic steatosis improved hepatic insulin sensitivity [Samuel et al., 2004].

We have not seen a study that shows an association between serum leptin levels and S. marianum supplementation, so this is the first study which demonstrates that $S$. marianum ameliorates increased leptin levels in rats. Leptin is produced by adipose tissue, and its level is closely correlated with the weight of adipose tissue [Friedman \& Halaas, 1998]. Therefore, the decreased plasma leptin level associated with S. marianum supplementation may be attributable to the decrease of adipose tissue induced by $S$. marianum. Leptin might contribute to hepatic steatosis by promoting insulin resistance and also by altering insulin signaling in hepatocytes, so as to promote increased intracellular fatty acids [Sheth et al., 1997]. These data, together with those of serum insulin and leptin levels clearly show that SME was able to partially inhibit some effects of HFD.

Limitations, however, exist in this study: firstly, we did not evaluate fecal lipid so we were unable to determine if SME caused a decrease in fat absorption. Secondly, SME was orally-administered to experimental groups and the same amount of distilled water was orally given to control groups but disturbing every day could be a stress factor for rats.

SME treatment may reverse the effects of a high-fat diet on BMI and this effect may be related to decreased fat absorption. Other possible mechanisms such as decreased fatty acid synthesis and increased fatty acid oxidation need further investigation. Finally, it will be important to clearly determine whether our observed effects occur in humans and whether SME consumption can be used as a tool to prevent the development of obesity and its comorbidities.

\section{CONCLUSIONS}

In summary, the present study has shown the potential protective action of SME on obesity-related diseases including cardiovascular disease and type 2 diabetes by ameliorating serum TC, LDL-C, HDL-C, TG, hsCRP, leptin and insulin concentrations. Results obtained in this study indicate the possibility of applying SME as a health-promoting food additive.

\section{ACKNOWLEDGEMENT}

This research was supported by Selcuk University Scientific Investigation Program. 


\section{REFERENCES}

1. Abdul S., Hussain R., Silymarin as an adjunct to glibenclamide therapy improves long-term and postprandial glycemic control and body mass index in type 2 diabetes. J. Med. Food, 2007, 10, 543-547.

2. Abenavoli L., Capasso R., Milic N., Capasso F., Milk thistle in liver diseases: past, present, future. Phytother. Res., 2010, 24, 1423-1432.

3. Amasyalı E., Kılıçlı F., Say R., Uygungelen B., Acıbucu F., The relation between non-alcoholic fatty liver disease and hs-CRP levels in patients with metabolic syndrome. Cumhuriyet Med. J., 2010, 32, 26-33 (in Turkish).

4. Barness L.A., Opitz J.M., Gilbert-Barness E., Obesity: genetic, molecular, and environmental aspects. Am. J. Med. Genet., 2007, 143A, 3016-3034.

5. Baquer N.Z., Glucose over utilization and under utilization in diabetes and effects of antidiabetic compounds. Anales de la Real Academia de Farmacia, 1998, 64, 147-180.

6. Bergmeyer H.U., Horder M., Moss D.W., Provisional recommendations on IFCC methods for the measurement of catalytic concentrations of enzymes. Part 3. Revised IFCC method of aspartate aminotransferase (L-Aspartate:2-oxoglutarate aminotransferase, EC 2.6.1.1) Clin. Chem., 1978, 24/4, 720-721.

7. BrahmaNaidu P., Nemani H., Meriga B., Mehar S.K., Potana S., Ramgopalrao S., Mitigating efficacy of piperine in the physiological derangements of high fat diet induced obesity in Sprague Dawley rats. Chem. Biol. Inter., 2014, 221, 42-51.

8. Bulló M., Casas-Agustench P., Amigó-Correig P., Aranceta J., Salas-Salvadó J., Inflammation, obesity and comorbidities: the role of diet. Publ. Health Nutr., 2007, 10, 1164-1172.

9. Chen I.S., Chen Y.C., Chou C.H., Chuang R.F., Sheend L.Y., Chiub C.H., Hepatoprotection of silymarin against thioacetamide-induced chronic liver fibrosis. J. Sci. Food Agric., 2012, 92, 1441-1447.

10. Crocenzi F.A., Pellegrino J.M., Pozzi E.J.S., Mottino A.D., Garay E.A.R., Roma M.G., Effect of silymarin on biliary bile salt secretion in the rat. Biochem. Pharmacol., 2000, 59, 1015-1022.

11. Dehmlow C., Erhard J., de Groot ., Inhibition of Kupffer cell functions as an explanation for the hepatoprotective properties of silibinin. Hepatology, 1996, 23, 749-754.

12. El Mesallamy H.O., Metwally N.S., Soliman M.S., Ahmed K.A., Abdel Moaty M.M., The chemopreventive effect of Ginkgo biloba and Silybum marianum extracts on hepatocarcinogenesis in rats. Cancer Cell Int., 2011, 11, 38.

13. Falasca K., Ucciferri C., Mancino P., Vitacolonna E., Tullio D., Pizzigallo E., Conti P., Vecchiet J., Treatment with silybin-vitamin E-phospholipid complex in patients with hepatitis $\mathrm{C}$ infection. J. Med. Virol., 2008, 80, 1900-1906.

14. Flanagan A.M., Brown J.L., Santiago C.A., Aad P.Y., Spicer J.L., Spicer M.T., High-fat diets promote insulin resistance through cytokine gene expression in growing female rats. J. Nutr. Biochem., 2008, 19, 505-513.

15. Fried M., Hainer V., Basdevant A., Buchwald H., Dietel M., Finer N., Greve J.W., Horber F., Mathus-Vliegen E., Scopinaro N., Steffen R., Weiner R., Widhalm K., Interdisciplinary European guidelines on surgery for severe obesity. Rozhl. Chir., 2008, 87, $468-476$.
16. Friedman J.M., Halaas J.L., Leptin and the regulation of body weight in mammals. Nature, 1998, 395, 763-770.

17. Galletti F., Barbato A., Versiero M., Iacone R., Russo O., Barba G., Siani A., Cappuccio FP., Farinaro E., della Valle E., Strazzullo P., Circulating leptin levels predict the development of metabolic syndrome in middle-aged men: an 8-year follow-up study. J. Hypertens., 2007, 25, 1671-1675.

18. Ghaffari A.R., Noshad H., Ostadi A., Ghojazadeh M., Asadi P., The effects of milk thistle on hepatic fibrosis due to methotrexate in rat. Hepat. Mon., 2011, 11, 464-468.

19. Gopalakrishnan R., Sundaram J., Sattu K., Pandi A., Thiruvengadam D., Silymarin attenuated mast cell recruitment thereby decreased the expressions of matrix metalloproteinases-2 and 9 in rat liver carcinogenesis. Invest. New Drug., 2009, 27, 233-240.

20. Grundy S.M., Obesity, metabolic syndrome and cardiovascular disease. J. Clin. Endo. Metab., 2004, 89, 2595-2600.

21. Haddad Y., Vallerand D., Brault A., Haddad P.S., Antioxidant and hepatoprotective effects of silibinin in a rat model of nonalcoholic steatohepatitis. Evidence Based Compl. Alt. Med., 2011, 2011, hep164.

22. Hamza N., Berke B., Cheze C., Agli A.N., Robinson P., Gin H., Moore N., Prevention of type 2 diabetes induced by high fat diet in the $\mathrm{C} 57 \mathrm{BL} / 6 \mathrm{~J}$ mouse by two medicinal plants used in traditional treatment of diabetes in the east of Algeria. J. Ethnopharmacol., 2010, 128, 513-518.

23. Kim J.Y., Nolte L.A., Hansen P.A., Han D.H., Ferguson K., Thompson P.A., Holloszy J.O., High-fat diet-induced muscle insulin resistance: relationship to visceral fat mass. Am. J. Physiol. Regul. Integr. Comp. Physiol., 2000, 279, R2057-R2065.

24. Kren V., Walterová D., Silybin and silymarin: new effects and applications. Biomed. Pap., 2005, 149, 29-41.

25. Lahiri-Chatterjee M., Katiyar S.K., Mohan R.R., Agarwal R., A flavonoid antioxidant, silymarin, affords exceptionally high protection against tumor promotion in the sencar mouse skin tumorigenesis model. Can. Res., 1999, 59, 622-632.

26. Lim D.W., Kim Y.T., Jang Y.J., Kim Y.E., Han D., Anti-obesity effect of Artemisia capillaris extracts in high-fat diet-induced obese rats. Molecules, 2013, 18, 9241-9252.

27. Li Volti G., Salomone S., Sorrenti V., Mangiameli A., Urso V., Siarkos I., Galvano F., Salamone F., Effect of silibinin on endothelial dysfunction and ADMA levels in obese diabetic mice. Cardiovasc. Diabet., 2011, 10, 62-70.

28. Maguire T., Haslam D., The Obesity Epidemic and its Management. 2010, Pharmaceutical Press, London, pp. 264-267.

29. Marović D., Elevated body mass index fatty liver. Srp. Arh. Celok. Lek., 2008, 136, 122-125.

30. Mao Z.M., Song H.Y., Yang L.L., Liu T., Li D.F., Zheng P.Y., Liu P., Ji G., Effects of the mixture of Swertia pseudochinensis Hara and Silybum marianum Gaertn extracts on $\mathrm{CCl}(4)$-induced liver injury in rats with non-alcoholic fatty liver disease. Zhong Xi Yi Jie He Xue Bao, 2012, 10, 193-199.

31. Mashmoul M., Azlan A., Yusof B.N.M., Khaza'ai H., Mohtarrudin N., Boroushaki M.T., Effects of saffron extract and crocin on anthropometrical, nutritional and lipid profile parameters of rats fed a high fat diet. J. Funct. Foods, 2014, 8, 180-187.

32. Montani J.P., Carroll J.F., Dwyer T.M., Antic V., Yang Z., Dulloo A.G., Ectopic fat storage in heart, blood vessels and kidneys 
in the pathogenesis of cardiovascular diseases. Int. J. Obes., 2004, 28, 58-65.

33. Novelli E.L., Diniz Y.S., Galhardi C.M., Ebaid G.M., Rodrigues H.G., Mani F., Fernandes A.A., Cicogna A.C., Novelli Filho J.L., Anthropometrical parameters and markers of obesity in rats. Lab. Anim., 2007, 41, 111-119.

34. Pittler M.H., Schmidt K., Ernst E., Adverse events of herbal food supplements for body weight reduction: systematic review. Obes. Rev., 2005, 6, 93-111.

35. Poirier P., Giles T.D., Bray G.A., Obesity and cardiovascular disease: pathophysiology, evaluation, and effect of weight loss: an update of the 1997 American Heart Association Scientific Statement on Obesity and Heart Disease from the Obesity Committee of the Council on Nutrition, Physical Activity, and Metabolism. Circulation, 2006,113, 898-918.

36. Pradhan S.C., Girish C., Hepatoprotective herbal drug, silymarin from experimental pharmacology to clinical medicine. Indian J. Med. Res., 2006, 124, 491-504.

37. Prakash P., Singh V., Jain M., Rana M., Khanna V., Barthwal M.K., Dikshit M., Silymarin ameliorates fructose induced insulin resistance syndrome by reducing de novo hepatic lipogenesis in the rat. Eur. J. Pharmacol., 2014, 727, 15-28.

38. Raja S., Ahmed K., Kumar V., Mukherjee K., Bandyopadhyay A., Mukherjee P., Antioxidant effect of Cytisus scorparius against carbon tetrachloride treated liver injury in rat. J. Ethnopharmacol., 2007, 109, 41-47.

39. Ramakrishnan G., Raghavendran H.R., Vinodhkumar R., Devaki T., Suppression of nitrosodiethylamine induced hepatocarcinogenesis by silymarin in rats. Chem. Biol. Interact., 2006, 161, 104-114.

40. Rautela G.S., Hall R.G., Jr Bekiesz C.L., Wermus G.R., A kinetic method for the rapid and automatic measurement of triglycerides in biological fluids. Clin. Chem., 1974, 20, 857-862.

41. Rautela G.S., Liedtke R.J., Automated enzymic measurement of total cholesterol in serum. Clin. Chem., 1978, 24, 108-114.

42. Salamone F., Galvano F., Marino A., Paternostro C., Tibullo D., Bucchieri F., Mangiameli A., Parola M., Bugianesi E., Volti G.L., Silibinin improves hepatic and myocardial injury in mice with nonalcoholic steatohepatitis. Digest. Liver Dis., 2012, 44, 334-342.

43. Samuel V.T., Liu Z.X., Qu X., Elder B.D., Bilz S., Befroy D., Romanelli A.J., Shulman G.I., Mechanism of hepatic insulin resistance in non-alcoholic fatty liver disease. J. Biol. Chem., 2004, 279, 32345-32353.

44. Shaw L.M., Stromme J.H., London J.L., Theodorsen L., IFCC methods for the determination of enzymes part 4. IFCC method for gamma-glutamyl transferase [(gamma-glutamyl)-peptide; amino acid gamma-glutamyl transferase, EC 2.3.2.2]. Clin. Chim. Acta, 1983, 135, 315F-338F.

45. Sheth S.G., Gordon F.D., Chopra S., Nonalcoholic steatohepatitis. Ann. Intern. Med., 1997, 126, 2, 137-145.

46. Shulman G.I., Cellular mechanisms of insulin resistance. J. Clin. Invest., 2007, 106, 171-176.

47. Skottova N., Krecman V., Simanek V., Activities of silymarin and its flavonolignans upon low density lipoprotein oxidizability in vitro. Phytother. Res., 1999, 13, 535-537.

48. Skottova N., Vecera R., Urbánek K., Vána P., Walterová D., Cvak L., Effects of polyphenolic fraction of silymarin on lipoprotein profile in rats fed cholesterol-rich diets. Pharmacol. Res., 2003, $47,17-26$.

49. Sobolova L., Skottova N., Vecera R., Urbanek K., Effect of silymarin and its polyphenolic fraction on cholesterol absorbtion in rats. Pharmacol. Res., 2006, 53, 104-112.

50. Soto C., Recoba R., Barrón H., Alvarez C., Favari L., Silymarin increases antioxidant enzymes in alloxan-induced diabetes mellitus in the rat pancreas. Comp Biochem Physiol. C Toxicol. Pharmacol., 2003, 136, 205-212.

51. Soto C., Mena R., Luna J., Cerbón M., Larrieta E., Vital P., Uría E., Sánchez M., Recoba R., Barrón H., Favari L., Lara A., Silymarin induces recovery of pancreatic function after alloxan damage in rats. Life Sci., 2004, 75, 2167-2180.

52. Tanaka S., Hayashi T., Toyoda T., High-fat diet impairs the effects of a single bout of endurance exercise on glucose transport and insulin sensitivity in rat skeletal muscle. Metabolism: Clin. Exp., 2007, 56, 1719-1728.

53. Terra X., Pallarés V., Ardèvol A., Bladé C., Fernández-Larrea J., Pujadas G., Salvadó J., Arola L., Blay M., Modulatory effect of grape-seed procyanidins on local and systemic inflammation in diet-induced obesity rats. J. Nutr. Biochem., 2011, 22, 380-387.

54. Trappoliere M., Federico A., Tuccillo C., de Sio I., Di Leva A., Niosi M., D’Auria M., Loguercio C., Effects of a new pharmacological complex (silybin + vitamin-E + phospholipids) on some markers of the metabolic syndrome and of liver fibrosis in patients with hepatic steatosis Preliminary study. Minerva Gastroenterol Dieto., 2005, 51, 193-199 (in Italian).

55. Tsai J.H., Liu J.Y., Wu T.T., Ho P.C., Huang C.Y., Shyu J.C., Effects of silymarin on the resolution of liver fibrosis induced by carbon tetrachloride in rats. J. Viral Hepat., 2008, 15, 508-514.

56. Vengerovskii A.I., Khazanov V.A., Eskina K.A., Vasilyev K.Y., Effects of silymarin (hepatoprotector) and succinic acid (bioenergy regulator) on metabolic disorders in experimental diabetes mellitus. Bull. Exp. Biol. Med., 2007, 144, 53-56.

57. Wagner H., Seligmann O., Liver therapeutic drugs from Silybum marianum. 1985, in: Advances in Chinese Medicinal Materials Research (eds. H.M. Chang, H.W. Yeung, W.W. Tso, A. Koo). World Scientific Publ., Singapore, pp.132-133.

58. Warnick GR., Wood P.D., National Cholesterol Education Program recommendations for measurement of high-density lipoprotein cholesterol: Executive summary. Clin. Chem., 1995, 41, 1427-1433.

59. Wei Y., Clark S.E., Morris E.M., Thyfault J.P., Uptergrove G.M., Angiotensin II-induced non-alcoholic fatty liver disease is mediated by oxidative stress in transgenic TG(mRen2)27(Ren2) rats. J. Hepatol., 2008, 49, 417-428.

60. Wroblewski F., LaDue J.S., Serum glutamic pyruvic transaminase in cardiac and hepatic disease. Proc. Soc. Exp. Biol. Med., 1956, 91, 569-571.

61. You J.S., Lee Y.L., Kim S.H., Kim S.H., Changa K.J., Ethanol extract of lotus (Nelumbo nucifera) root exhibits an anti-adipogenic effect in human pre-adipocytes and anti-obesity and anti-oxidant effects in rats fed a high-fat diet. Nutr. Res., 2014, 34, 258-267.

Submitted: 29 May 2014. Revised: 20 October, 25 November and 5 December 2014. Accepted: 11 December 2014. Published online: 25 November 2015. 
